\title{
Innovative Approach to Flame Retardant Cotton Fabrics with Phosphorus Rich Casein via Layer-by-Layer Processing
}

\author{
Sechin Chang*, Brian Condon, Jade Smith, Sunghyun Nam \\ United States Department of Agriculture, Agricultural Research Service, Southern Regional Research Center, New Orleans, USA \\ Email address: \\ sechin.chang@usda.gov (S. Chang), brian.condon@usda.gov (B. Condon), jade.smith@usda.gov (J. Smith), \\ sunghyun.nam@usda.gov (S. Nam) \\ ${ }^{*}$ Corresponding author
}

To cite this article:

Sechin Chang, Brian Condon, Jade Smith, Sunghyun Nam. Innovative Approach to Flame Retardant Cotton Fabrics with Phosphorus Rich Casein via Layer-by-Layer Processing. International Journal of Materials Science and Applications. Vol. 8, No. 5, 2019 , pp. 81-89. doi: 10.11648/j.ijmsa.20190805.12

Received: September 6, 2019; Accepted: September 25, 2019; Published: October 23, 2019

\begin{abstract}
Flame retardant behaviour was imparted using the layer-by layer assemblies of phosphorus rich casein milk protein with eco-friendly inorganic chemicals on cotton fabrics. The cotton twill fabrics were prepared using two solutions; a mixture of positively charged branched polyethylenimine (BPEI) with urea and diammonium phosphate (DAP), and negatively charged casein. Layer-by-layer assemblies for flame retardant properties were applied using the pad-dry-cure method, and each coating formula was rotated for 20 bi-layers. The effectiveness to resist flame spread on treated fabrics was evaluated using vertical (ASTM D6413-08) and $45^{\circ}$ angle flammability test (ASTM D1230-01) methods. In most case, char lengths of fabrics that passed the vertical flammability tests were less than $50 \%$ of the original length, and after-flame and after-glow times were less than one second. Thermal properties were tested the extent of char produced by untreated and treated fabrics at $600{ }^{\circ} \mathrm{C}$ by thermogravimetric analysis (TGA). Micro-scale combustion calorimeter (MCC) and Limiting oxygen indices (LOI, ASTM D2863-09) were also assessed. All untreated fabrics showed LOI values of about $21 \%$ oxygen in nitrogen. LOI values for the treated casein with BPEI/urea/DAP fabrics were greater than 29-34\% between 5.80-9.59 add on wt $\%$. Their structural characterizations were revealed by TGA/FT-IR and SEM methods. The treated fabrics exhibited improved thermal stability, as evidenced by increased ignition times and lower heat release rates. The results of this study show that flame retardant nanocoatings can be readily applied to textile fabrics using a continuous process that is ideal for commercial and industrial applications.
\end{abstract}

Keywords: Layer-by-Layer, Cotton, Flame Retardant, TGA/FTIR, Thermogravimetric Analysis

\section{Introduction}

Cotton fiber is broadly used to produce clothing, home furnishings, and various industrial products, such as medical supplies, industrial fiber, and canvases. While cotton is highly valued for its softness, breathability, and ability to absorb moisture, cotton is generally more combustible than most synthetic fibers $[1,2]$. To meet fire safety regulations and expand the use of cotton in textile applications that require flame resistance, a significant number of flame-retardant treatments for textiles were developed in the second half of the last century. The majority of these flame-retardant treatments can be classified into four distinct groups: inorganic, halogenated organic, organophosphorus, and nitrogen based [3-6]. Earlier works on phosphorus-nitrogen systems showed that such combinations produced greater flame resistance in cotton textiles at a lower level of phosphorus than when phosphorus was used alone [7, 8]. Unlike the halogencontaining compounds, which generate toxicity or may produce toxic gases, corrosive smoke, or harmful substances, the phosphorus-containing flame retardants are known to transform into phosphoric acid during combustion or thermal 
degradation. This further causes the formation of non-volatile phosphoric acid that can react with the decomposing polymer by esterification and dehydration to promote the formation of char residue [9]. The char residue can act as a barrier to protect the underlying polymer from attack by oxygen and radiant heat, achieving the purpose of extinguishing the fire.

Casein is the major fraction milk protein obtained as a coproduct during the production of skim milk. Casein is in a family of phosphoproteins in their micelle structure, which is beneficial due to the high concentrations of phosphorus and nitrogen, potential flame retardant additives in cotton cellulosic materials $[10,11]$. In earlier research, phosphorus-nitrogen synergism containing urea-derivative compounds created better flame retardant properties. Diammonium phosphate (DAP) is often used as a flame retardant chemical to yield semi-durable finishes on cotton $[6,12]$. It causes a drop in the temperature of combustion of the material, decreases the highest rates of weight loss, and gives higher char yields. In an effort to make flame retardant cotton fabrics, urea and DAP were used for phosphorus and nitrogen components because they are economic and environmentally friendly compounds. As a non-durable or semi-durable flame retardant, DAP is broadly used on infrequently washed or disposable products [7]. Literature states that DAP is the most effective within nondurable and durable flame retardants in delivering flame retardant properties to cellulosic materials and in yielding char [13].

One of the newest methods of textile surface modification is the layer-by layer (LBL) method. Initially, this method was used for materials other than textiles. The usage of multilayered polymeric films offered the possibility of creating new types of materials with enhanced levels of reproducibility and controlled architectures. The most important principle of the LBL method consists in alternately depositing oppositely charged layers of polyelectrolytes, which ion-pair through electrostatic forces. The LBL process was created by $G$. Decher [14, 15] and others [16, 17], who based the approach on the alternating deposition of charged anionic and cationic polyelectrolytes to create nanometer thin multilayer coatings on the surface of a material via electrostatic interactions. In recent years, researchers have used the LBL process to modify the surface of textile fabrics to impart or improve upon numerous surface properties, including mechanical integrity [18, 19], UV-protection [20], hydrophobicity/hydrophilicity $[21,22]$, dyeability [23], antimicrobial [24, 25], and flame retardancy [26-29].

The nanocoating of textile materials to impart flame retardancy is a relatively new field, and although the use of LBL technology to modify the surfaces of textile fabrics and fibers has been widely studied in recent years, the overall process is still not well understood. Previous LBL flame retardant research has primarily focused on the development and characterization of simple clay/polyelectrolyte thin films with no additional small molecule flame retardants added to the formulation. In addition, current laboratory-based LBL techniques that use multiple immersion/rinse cycles to develop multilayer coatings can be labor-intensive and time-consuming, which often limits the use of the coating technique in commercial applications. In the present study, an attempt was made to improve the flame retardancy of cotton fabrics by the deposition of multilayer films containing BPEI, DAP, urea, and casein nanoparticles using a newly developed continuous LBL self-assisted process. The imparted flame retardancy of the cotton fabrics with the deposited casein nanolayers was tested using thermogravimetric analysis (TGA), limiting oxygen index (LOI, ASTM D2863-09) [30], 45 angle (clothing textiles test, ASTM D1230-01) [31], vertical flammability testing (ASTM D6413-11), and microscale combustion calorimeter (MCC) [32]. In order to understand their thermal degradation, the TGA/FTIR technique was used to study the control and treated cotton samples. Scanning electron microscopy (SEM) measurements were performed to verify the presence of the deposited nanolayers and study the morphology of the various nanocoatings.

\section{Experimental}

\subsection{Materials}

Commercial grade diammonium phosphate (DAP) and urea were obtained from Magnolia Chemical Co. (New Orleans, LA, USA). Casein powder (casein sodium salt from bovine milk, 20 micro), sodium hydroxide, and branced polyethylenimine (BPEI, with a molecular weight of 1200) were purchased from Aldrich and used as received. The reagents were used without further drying or purifying. In the testing experiments, mercerized twill $\left(258 \mathrm{~g} / \mathrm{m}^{2}\right.$, Style 423$)$ cotton fabrics were obtained from Test Fabrics Inc. and used as received. This fabric was desized (starches removed), bleached, and free of all resins and finishes.

\subsection{Layer-by-Layer Processing for Fabric Treatment}

A modified laboratory pad-steam unit (Mathis, model PSA-HTF, Figure 1) was used to apply the 20 bilayer (BL) casein-BPEI-DAP-urea coatings to the twill cotton fabrics in a continuous layer-by-layer self-assisted process. The steam range of the pad-steam unit was bypassed, and the fabrics were directly loaded onto the rinsing section of the unit, which consisted of two separate rinsing chambers. The fabrics were cut to a width of 16 inches $(405 \mathrm{~mm})$ for processing, and hand fed through the individual rollers of the rinsing chambers before the ends were sewn together to create a continuous piece of fabric. The first rinsing chamber was filled with $10 \mathrm{~L}$ of an aqueous-based $1.5 \mathrm{wt} \%$ BPEI solution (cationic) containing $10-20 \quad \mathrm{wt} \%$ urea and diammonium phosphate (DAP). The second chamber was filled with $10 \mathrm{~L}$ of an aqueous solution of $1.5 \mathrm{wt} \%$ Casein (anionic) that was brought to $\mathrm{pH} \sim 11$ using sodium hydroxide $(\mathrm{NaOH})$. The water was added to the casein and the solutions allowed sitting for 10 minutes to minimize clumping of the casein. The casein nanoparticles were dispersed in deionized water using a shear mixer (Silverson, model L5MA) set to $3000 \mathrm{rpm}$, and a stable colloidal solution was obtained after 3 $\mathrm{h}$ of mixing. Upon completion of the deposition process, the 
rinsing chambers of the pad-steam unit were drained, and the fabric was cut for removal. The $20 \mathrm{BL}$ coated cotton fabrics were dried at $110^{\circ} \mathrm{C}$ and cured at $140^{\circ} \mathrm{C}$ via a continuous dryer (Mathis, model KTF-S) set to a speed of $2 \mathrm{~m} / \mathrm{min}$. Once removed from the curing dryer, the fabric was immediately placed in a desiccator to cool to room temperature, and its weight was obtained after cooling. All samples were weighed before and after the treatment, and the values were fitted to the equation (1) to obtain add-on percents (or add-on levels):

$$
\text { Add-on }(\%)=\left[\left(\text { weight }_{\text {after drying }}-\text { weight }_{\text {before treatment }}\right) / \text { weight }_{\text {before treatment }}\right] \times 100
$$

\subsection{Thermal Gravimetric Analysis (TGA)}

Untreated control and treated fabric samples with casein and urea/DAP were tested by thermogravimetric analysis (TGA) for thermal stability (TA Instrument, Q500). Under a continuous nitrogen atmosphere, samples $(5-7 \mathrm{mg})$ were analyzed at a heating rate of $10^{\circ} \mathrm{C} / \mathrm{min}$ starting at room temperature and ending at $600^{\circ} \mathrm{C}$.

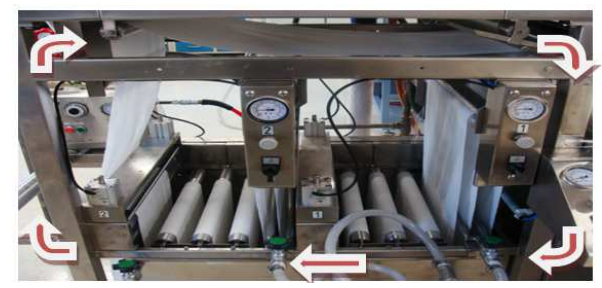

Figure 1. Picture of the Layer-by-Layer self-assisted process used to apply the 20 bilayers casein-BPEI-DAP-urea coatings. Arrows indicate the directional flow of the fabric as it is processed.

\subsection{Micro-scale Combustion Calorimeter (MCC)}

The MCC (Govmark, MCC-2) consisted of a sample mounting post, which contained a thermocouple in the post with its tip at the top directly below the sample holder to monitor temperature. A small fabric sample was inserted in a ceramic cup and placed on the sample holder. This assembly was then inserted into a furnace so that everything was inside the furnace. The heat release combustion (HRC) correlated directly to flow rates of the gases involved in the combustion process and to the oxygen concentrations. HRC used oxygen reduction as a determining factor.

\subsection{Thermogravimetric Analysis/Fourier Transform Infrared (TGA/FTIR) Spectroscopy}

The TGA-FTIR experiment was conducted by a TA Instruments Q500 thermogravimetric analyzer and a Bruker Tensor-27 spectrometer. In this experiment, 5-8 $\mathrm{mg}$ of each sample were heated between 20 and $550^{\circ} \mathrm{C}$ in the thermogravimetric analyzer at a rate of $10^{\circ} \mathrm{C} / \mathrm{min}$ and under a nitrogen flow rate of $60 \mathrm{~mL} / \mathrm{min}$. The resulting volatile decomposition products then traveled through a transfer line to reach the gas cell of the FTIR spectrometer. Although the TGA experiment investigated the thermal degradation of the samples from 20 to $600^{\circ} \mathrm{C}$, the FTIR experiment examined the gaseous products released during the main degradation ranging from 100 to $500^{\circ} \mathrm{C}$. Both transfer line and gas cell were maintained at $200^{\circ} \mathrm{C}$. When the evolved gases reached the gas cell, they were analyzed by a liquid-nitrogen cooled MCT detector, which was equipped with $\mathrm{Zn}$ Se windows. The gas components were then recorded as the absorption peaks in the $4000-600 \mathrm{~cm}^{-1}$ region at a resolution of four wavenumbers. This data was obtained every 5 degree increment along the TGA heating profile, and there was a 30s delay between the timed measurements for the FTIR. When the experiment was completed, the data was analyzed using the Opus software, which measures the intensity of the absorption band (representing the functional groups) as a function of temperature. For analytical purposes, OriginLab 9 software was utilized to retain the three dimensional images of the FTIR spectra.

\subsection{Flammability Tests and Limiting Oxygen Index (LOI)}

Control twill and treated fabrics were subjected to the vertical flammability (The Govmark Organization, Inc.), $45^{\circ}$ angle flammability (The Govmark Organization, Inc.) and LOI (Bynisco Polymer test) tests. In these tests, the specimen sizes were $30 \times 9,15 \times 6$ and $13 \times 6 \mathrm{~cm}$ for vertical, $45^{\circ}$ angle flammability, and LOI, respectively. In the $45^{\circ}$ angle flame test, a strip of fabric was inserted in a frame and held in a special apparatus at an angle of $45^{\circ}$. A standardized flame was applied to the surface near the lower end for 10 seconds. The time required for the flame to travel the length of the fabric and break the trigger string was recorded, as well as the fabric's physical reaction at the ignition point. In the vertical flame test, a specimen was positioned vertically above a controlled flame and exposed for a 12 second specified time, and an afterglow time was measured. Char length was measured under a specified force and any evidence of melting or dripping was noted. In the LOI test, a small sample of fabric was supported vertically in a mixture of oxygen and nitrogen flowing upwards through a transparent chimney. When the upper end of the sample was ignited, the subsequent burning behavior of the sample was observed to compare the period for which burning continued or the length of sample burned. Minimum concentration of oxygen was determined by testing a series of samples in different oxygen concentrations.

\subsection{Scanning Electronic Microscopy (SEM)}

Unburned samples and samples from burned areas of the control and treated fabrics before and after vertical flammability test were examined using the Philips XL30 ESEM with magnifications between $792 \mathrm{x}-1500 \mathrm{x}$ and a setting of $12 \mathrm{kV}$. For analysis purpose, all samples were coated with gold.

\section{Results and Discussion}

\subsection{Fabric Treatment}

The multilayer continuous deposition process consisted of two steps, the immersion of the cotton fabrics in the $1.5 \mathrm{wt} \%$ 
BPEI/urea/DAP solution, which passed through a roller, immediately followed by immersion of the fabrics in the 1.5 $w t \%$ Casein solution, which also passed through a roller. The two steps were continuously repeated for each formulation, without rinsing, for a total of 20 cycles using a roller speed of $2 \mathrm{~m} / \mathrm{min}$ and a pad pressure of $3 \mathrm{bar}(300 \mathrm{kPa})$. Formulation and percent add on values (wt\%) following wet pickup, drying, curing, and reconditioning of 20 bilayer coated mercerized twill fabric samples are shown in Table 1. 20 bilayers (BL) casein-BPEI/urea/DAP coatings solutions were prepared as following: $1.5 \%$ casein solution in deionized water and $1.5 \%$ BPEI, $10 \%$ urea and $10 \%$ DAP in deionized water (CM-10 sample); $1.5 \%$ casein solution in deionized water and $1.5 \%$ BPEI, $15 \%$ urea and $15 \%$ DAP in deionized water (CM-15 sample); $1.5 \%$ casein solution in deionized water and 1.5\% BPEI, 20\% urea and 20\% DAP in deionized water (CM-20 sample). Formulations of casein with BPEI, urea, DAP treatment; CM-10, CM-15 and CM-20 showed 5.80, 7.22 and 9.59 add-ons ( $w t \%$ ) for twill cotton fabrics, respectively.

Table 1. Fabric treatment formulations and TGA data for untreated and treated twill cotton fabrics.

\begin{tabular}{lllll}
\hline Samples & Formulations (casein: BPEI: urea: DAP) & Average add-ons (wt\%) & Onset of Degradation, ${ }^{\circ} \mathbf{C}$ & Char\% at 600 \\
\hline Control & N/A & $\mathbf{0}$ & $\mathbf{3 3 0 . 6 8}$ & $\mathbf{1 3 . 9 7}$ \\
\hline CM-10 & $(1.5 \%: 1.5 \%: 10 \%: 10 \%)$ & 5.80 & 275.24 & 31.11 \\
CM-15 & $(1.5 \%: 1.5 \%: 15 \%: 15 \%)$ & 7.22 & 274.94 & 33.97 \\
CM-20 & $(1.5 \%: 1.5 \%: 20 \%: 20 \%)$ & 9.59 & 276.60 & 35.77 \\
\hline
\end{tabular}

\subsection{Thermogravimetric Analysis (TGA)}

Also shown in Table 1, are the TGA values for onset of degradation temperature $\left({ }^{\circ} \mathrm{C}\right)$ and char yield $\left(\%\right.$ at $\left.600{ }^{\circ} \mathrm{C}\right)$ for untreated and treated cotton fabrics. Figure 2 compiles TGA curves from room temperature to $600^{\circ} \mathrm{C}$ of the control and treated fabrics. In a nitrogen atmosphere, all the untreated and treated fabrics exhibited mostly mono mass-loss curves. With regard to the control, the TGA curve showed the loss of mass starting around $330-340^{\circ} \mathrm{C}$, then displays a turning point at $360^{\circ} \mathrm{C}$, which is where the rate of its mass loss reaches its maximum. It then continued losing more weight until it reaches $86 \%$ weight loss close to $600^{\circ} \mathrm{C}$. During this process, cotton produced volatiles, including combustible and non-combustible species at around $350^{\circ} \mathrm{C}$. At higher temperatures, the degradation generated a smouldering phenomenon leading to a slower mass loss [33]. According to
Figure 2, when twill fabrics were treated, they showed onsets of degradation between 274.94 and $276.60^{\circ} \mathrm{C}$, and provided char yields between 31.11 and $35.77 \%$. Decomposition temperatures of treated fabrics were lower than untreated control fabrics. This may be due to phosphonic acid derivatives accelerating fabric degradation. From the data in Table 1, it is evident that the char yields generated by higher add-ons (wt $\%$ ) are greater than those produced by lower addons ( $\mathrm{wt} \%$ ) due to the higher phosphorus and nitrogen contents. Chars protected against heat and flame propagation because they generated thermally stable cohesive phases having decomposition temperatures that exceeded the temperatures of the oxidizing zones of flames. Furthermore, chars were intumescing. They foamed and released gases that suppressed flammability. Therefore, it is very important to produce flame retardants that support intumescing and char formation $[34,35]$.

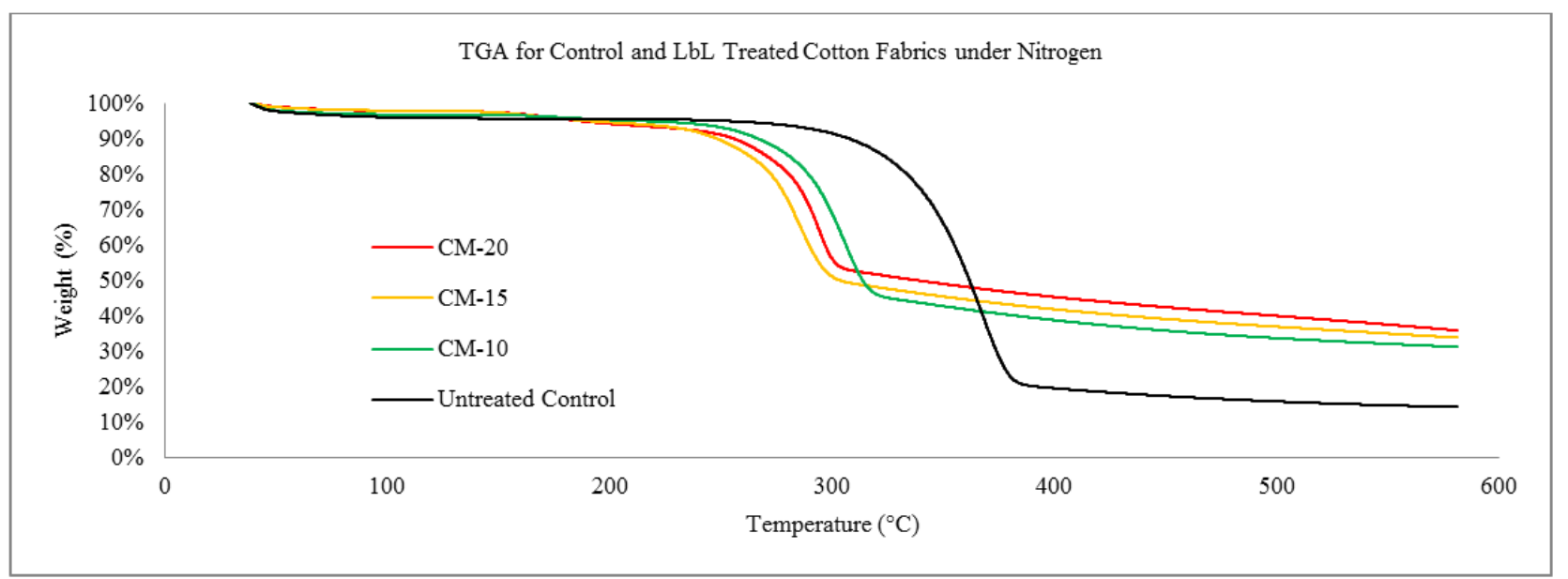

Figure 2. Degradation thermogram curves of the untreated control and treated twill cotton fabrics coated with 20 bilayers (CM-10, CM-15, and CM-20).

The onset of degradation of the treated fabrics initiated roughly around $270^{\circ} \mathrm{C}$. Evidently, the flame retardants lowered the heat resistance of the bulk material when compared to the control. Thermal degradation curves of treated fabrics normally comprise of at least two stages: the first is the degradation of the flame retardants, the chemicals, and the second is the degradation of main materials, the fabrics. Depending on concentration of the flame retardants on the fabrics, the first stage may or may not be obvious. It is known that phosphorus additives reduce the onset 
temperature for the second stage of treated cellulose by 50 $150^{\circ}[36,37]$. Again, phosphorus-nitrogen containing flame retardants obviously promoted char generation, and therefore, flame resistance in the treated fabrics.

\subsection{Microscale Combustion Calorimeter (MCC)}

HRR (heat release rate) versus temperature of the untreated control fabric and casein with BPEI/urea/DAP treated fabrics are shown in Figure 3. The flammability parameters, heat release combustion (HRC), total heat release (THR), and temperature of maximum of heat release combustion $\left(\mathrm{T}_{\max }\right)$, were computed and are presented in Table 2. The thermal decomposition of the untreated control sample started around $300^{\circ} \mathrm{C}$. The thermal decomposition as indicated by rising $\mathrm{HRC}$ strengthened as the temperature increased. Then, it attained a maximum point at $390.0^{\circ} \mathrm{C}$ and ended around $420^{\circ} \mathrm{C}$ with an approximate value of $12.00 \mathrm{~kJ} / \mathrm{g}$ in THR. When treated using the casein with BPEI/urea/DAP, cotton fabric showed a substantial reduction in THR, HRC and $\mathrm{T}_{\max }$ values. In Table 2, as the concentrations of CM-10, CM-15 and CM-20 increased, the initial decomposition temperature, THR, and $\mathrm{HRC}$ values all continuously decreased. All treated fabrics had lower THR, HRC and $\mathrm{T}_{\max }$ values than the untreated control. The protective layer then prevented the cotton fabrics from igniting, and reduced the normal thermal degradation of cotton fabrics and structural disintegration of the char to release volatiles and gases. Once the urea had burned, the main material started to burn and gave rise to the second peaks at around $250-320^{\circ} \mathrm{C}$. These peaks on the same shoulder slightly decreased with increasing add-on values from 5.80 to $9.59 \mathrm{wt} \%$.

Table 2. Microscale combustion calorimetry (MCC) data of control and treated fabrics (reported value is the average from three observations).

\begin{tabular}{llllll}
\hline Samples & Add-ons (wt\%) & HRC (J/gK) & pHRR (J/gk) & THR (KJ/g) & T $_{\max }\left({ }^{\circ} \mathbf{C}\right)$ \\
\hline Control & 0 & 270.0 & 269.4 & 12.0 & 390.0 \\
CM-10 & 5.80 & 136.3 & 136.6 & 3.5 & 304.5 \\
CM-15 & 7.22 & 122.3 & 122.5 & 3.2 & 303.9 \\
CM-20 & 9.59 & 100.5 & 100.6 & 2.5 & 300.1 \\
\hline
\end{tabular}

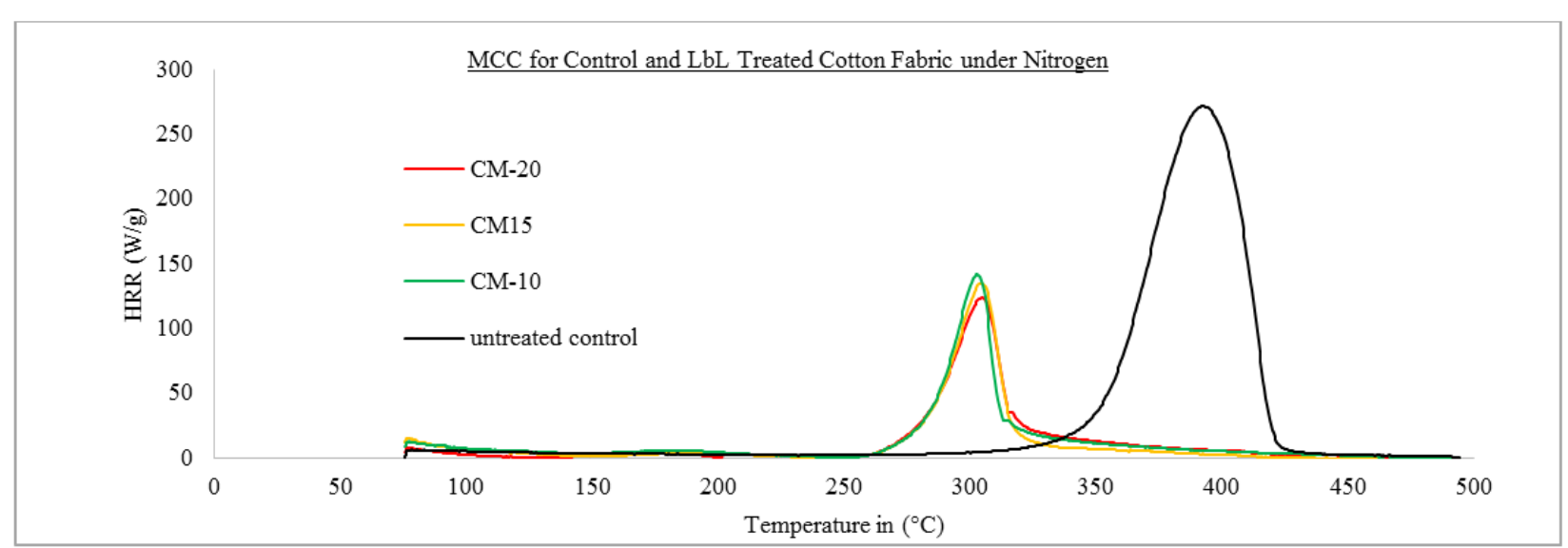

Figure 3. Microscale combustion calorimeter (MCC) graphs of heat release combustion curves for untreated control and treated samples of casein with BPEI/urea/DAP at various add-ons (wt\%), CM-10, CM-15, and CM-20.

\subsection{Pyrolysis Volatiles Analysis During Thermal Decomposition by TGA/FTIR}

In order to further discover the thermal degradation mechanism of the casein with BPEI/urea/DAP treated cotton fabric, TGA-FTIR was used to study the pyrolysis volatiles during thermal decomposition. By coupling with TGA, FTIR can detect the real-time gaseous products released in the pyrolysis process. During the experiment, the FTIR data were plotted one on top of the other with a total of 70 scans to form a $3 \mathrm{D}$ spectrum in which the evolution of gas products were shown as a function of both wavenumber and temperature. TGA-FTIR spectra output from higher add-on CM-20 treated sample and the corresponding FTIR spectra under different temperatures are shown in Figure 4. As for these treated cotton fabrics, no pyrolysis product was detected below $250^{\circ} \mathrm{C}$. After that, most of absorption bands began to appear at $290^{\circ} \mathrm{C}$. The gases released are mainly water vapor $(\sim 3900-3500$ and $\left.1770-1550 \mathrm{~cm}^{-1}\right)$, hydrocarbon $\mathrm{OH}$ and $\mathrm{N}-\mathrm{H}$ for urea and DAP ( 3400-3100 $\left.\mathrm{cm}^{-1}\right)$, hydrocarbon $\mathrm{CH}(\sim 3010-2750$ $\left.\mathrm{cm}^{-1}\right), \mathrm{CO}_{2}\left(\sim 2360-2310 \mathrm{~cm}^{-1}\right)$, some hydrocarbon $\mathrm{CO}$ $\left(\sim 1850-1600 \mathrm{~cm}^{-1}\right), \mathrm{C}=\mathrm{O}$ (urea, $\sim 1740 \mathrm{~cm}^{-1}$ ), N-H (urea, $\sim 1610 \mathrm{~cm}^{-1}$ ), C-N (urea, $\sim 1430 \mathrm{~cm}^{-1}$ ), and a mix of P-O stretching (DAP, $\sim 1250-800 \mathrm{~cm}^{-1}$ ). They are the products of the reduction of the cellulose molecule, the appearance of free radicals, oxidation, dehydration, decarboxylation, decarbonylation and decomposition of cellulose to tarry pyrolyzate-containing levoglucosan, which vaporizes and then decomposes at a later time or higher temperature [38, 39]. 



Figure 4. 3D TGA-FTIR (top) and the corresponding FTIR spectra (bottom) of volatiles released under different temperatures for CM-20 treated samples.

\subsection{Flame Retardant Properties (LOI, Vertical and $45^{\circ}$ Angle Flammability Tests)}

Limiting oxygen index (LOI), vertical and $45^{\circ}$ angle flammability tests are important in the evaluation of the flame retardant properties for treated cotton fabrics. The details of all three tests have been described elsewhere. LOI values indicate the minimum amount of oxygen needed to sustain a candle-like flame when a sample is burned in an atmosphere of oxygen and nitrogen. Textiles are considered to be flammable when LOI values are below $21 \%$ oxygen in nitrogen and are considered to be flame-retardant when LOI values fall in the range of $26-28 \%$. At these LOI values, flame retarded test fabric samples are expected to pass open flame tests in either the horizontal or vertical direction [34]. Passing an open flame test means that the ignited test sample self extinguished following a very short after-flame time, the sample did not glow after the flame extinguished by itself, and showed a char length that did not equal the length of the test sample. In Table 3, the average LOI values for all samples are provided. LOI values of untreated fabrics give 21 $\pm 1 \%$ oxygen in nitrogen. LOI values for treated fabrics with casein and BPEI/urea/DAP yield $34 \pm 1 \%, 32 \pm 1 \%$, and $29 \pm$ $2 \%$ when add-on values are $9.59 \mathrm{wt} \%, 7.22 \mathrm{wt} \%$ and $5.80 \mathrm{wt} \%$. The values for LOI increased in Table 3 before reaching a limiting value with respect to add-on, which strengthens the case for concentration of formulations that afford both higher phosphorus and nitrogen content and crosslinking of polymer for improved flame resistance. Figure 5 and Figure 6 show images and test data from $45^{\circ}$ angle and vertical flame tests. Following a 12 second exposure to flame in the vertical flammability test, most of the treated fabric samples showed no observable after-flame or after-glow times and char lengths were less than half the sample length. During the vertical testing, there was no occurrence of afterglow burning upon the removal of the flame, as well as no melting or dripping during the burning of all samples. From Figure 6, it is obvious that all treated fabrics had shorter char length and after-flame and after-glow time when compared with the control. All of the treated sample types passed the vertical flame test regardless of addon $w t \%$. For all of these cases, the char lengths of treated fabrics were $<50 \%$ of the original length of $30 \mathrm{~cm}$, and the after-flame and after-glow times were between 0 and $2 \mathrm{~s}$. 
Flammability requirements for all clothing textiles, before sale or introduction into trade, are instituted in the $45^{\circ}$ angle flammability test. The standard offers a consistent method to test textiles, and divides textile products used for clothing into three classes of flammability performance, thus limiting the use of flammable clothing in textiles. During the test procedure, a $16 \mathrm{~mm}$ (5/8 in) flame was positioned to touch the bottom of a specimen fixed at a $45^{\circ}$ angle for 10 seconds. The fabric sample burned its full length or until the thread that stopped the timer was broken, a distance of $127 \mathrm{~mm}$ (5 in). Class 1 or 2 specimens meet the requirements of the standard. Class 3, rapid and intense burning, does not meet the requirements of the standard. Figure 6 shows that untreated control fabric was completely burned and was totally consumed during the test. The test also showed the effectiveness of CM-10, CM-15 and CM-20 with 5.80-9.59 add ons (wt\%). None of the treated CM-10, CM-15 and CM20 samples ignited once exposed to the flame. Therefore, based on the classifications for textile products, all treated fabric samples are class 1, and are suitable for clothing due to slow burning or no combustibility.

Table 3. LOI (ASTM D2863-09) and $45^{\circ}$ angle flammability (ASTM D-1230-01) of different add-ons (wt \%) of treated fabrics. All reported values for $45^{\circ}$ angle tests are data from two observations on the same fabric type.

\begin{tabular}{llll}
\hline Samples & Add-ons (wt\%) & Average LOI (vol\%) (\# of trials) & $\mathbf{4 5}^{\circ}$ angle flammability Classification \\
\hline Control & 0 & $21 \pm 1(3)$ & Class $3^{(3)}$ \\
CM-10 & 5.80 & $29 \pm 2(3)$ & ${\text { Class } 1^{(a)}, \text { DNI }}^{(b)}$ \\
CM-15 & 7.22 & $32 \pm 1(3)$ & Class 1, DNI \\
CM-20 & 9.59 & $34 \pm 1(3)$ & Class 1, DNI \\
\hline
\end{tabular}

(a) Class 1: textiles are considered by the trade to be generally acceptable for apparel and are limited to the following:

1. A flat fiber surface with an average time of flame spread in the test of $3.5 \mathrm{~s}$ or more

2. A raised fiber surface with an average time of flame spread in the test of more than $7 \mathrm{~s}$ or that burn with a surface flash (time of flame spread less than $7 \mathrm{~s}$ ), provided the intensity of the flame is insufficient to ignite, char or melt the base fabric

(b) DNI: did not ignite. Average time in seconds of flame spread for specimens of fabric which ignite as received. If specimen does not ignite, DNI is reported for the sample.

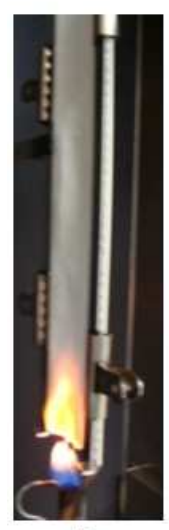

5s
Untreated control fabric

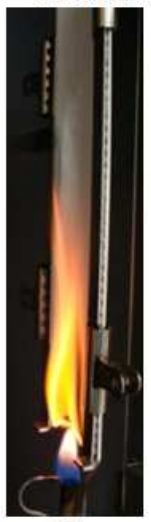

$10 \mathrm{~s}$

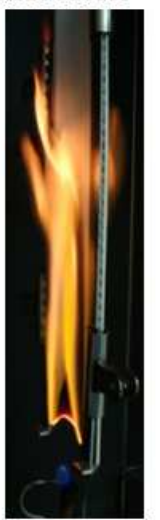

$15 s$

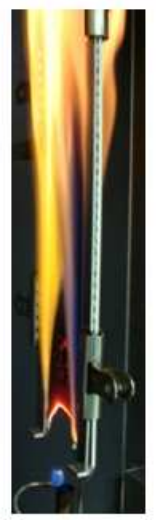

$20 s$

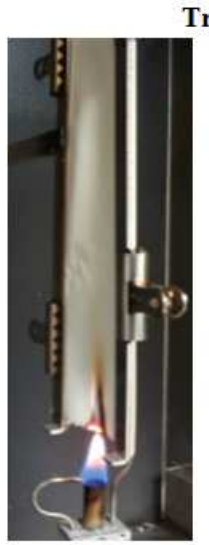

$5 \mathrm{~s}$

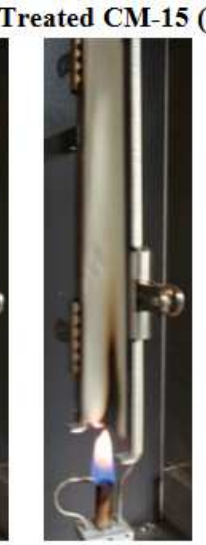

$10 \mathrm{~s}$

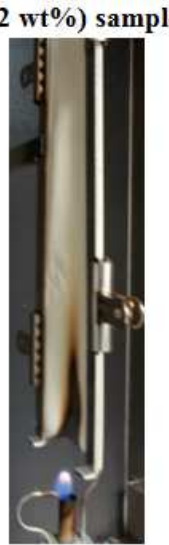

$15 s$

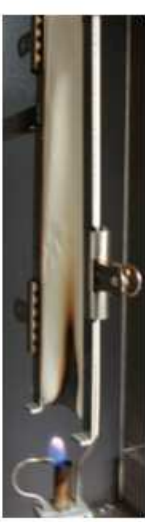

20s

Figure 5. Picture of control untreated twill fabric (left) and treated twill fabric (7.22 wt\% add-on, CM-15, right) during vertical flammability test by ASTM D6413-11 method.

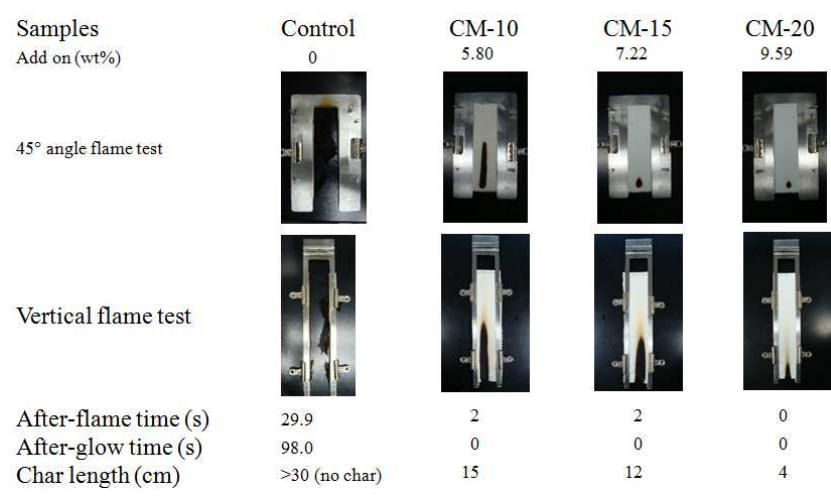

Figure 6. Summaries of $45^{\circ}$ angle (ASTM D-1230-01) and vertical (ASTM D-6413-11) flammability tests for different add-ons (wt\%) of treated fabrics. All values for $45^{\circ}$ angle and vertical tests are averages from two observations on the same fabric type.

\subsection{Scanning Electron Microscope (SEM)}

To investigate morphology and distribution of the $20 \mathrm{BL}$ coating, the cotton fabrics used in this study were imaged before and after LBL treatment via electron microscopy. The SEM images of the untreated control (top) and 20 BL treated (bottom) cotton fabrics are shown in Figure 7. The fibers of the untreated fabrics were smooth and generally free of defects. Under the influence of flame and heat, the shape and the appearance of the control untreated fibers were completely destroyed. The LBL treated fibers, however, exhibited a noticeable change in surface morphology and developed particulate-like aggregates on the surface, indicating a successful deposition of multiple polyelectrolyte casein bilayers. The SEM images of the treated fabrics illustrate that the $20 \mathrm{LBL}$ deposition process resulted in a 
thick coating that fully covered the cotton fabric surfaces. The appearance of this layer may be due to the creation of gases formed during the burning mechanism of the chemical components of flame retardants during the thermal decomposition. This result indicates that the structure of the chars on the surface of each fiber provides the resistance of heat transfer, and retards the degradation of underlying materials effectively; therefore, combustion cannot be selfsustained.
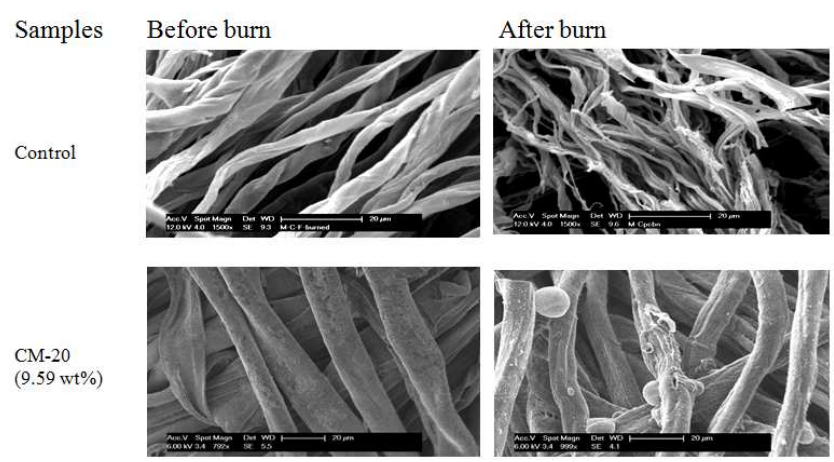

Figure 7. SEM Micrographs of untreated control (top) and highest add-on (CM-20) fabrics before burn (left) and after burn (right) at a magnification between $792 x-1500 x$

\section{Conclusions}

Layer-by-layer self-assembly has been successfully used to apply a wide variety of functional nanocoatings to textiles, but the deposition process is often time-consuming and laborintensive. In this work, a continuous LBL self-assisted deposition process was developed and used to apply flameretardant nanocoatings to cotton fabrics. A total of 40 alternating layers (20 bilayers) of casein milk protein nanoparticles with $\mathrm{BPEI} /$ urea/DAP were applied to the fabrics from aqueous solution using a modified pad-steam unit. SEM imaging of the treated fabrics revealed that the continuous LBL deposition process produced even coatings that completely covered fabrics. The flame retardant properties of the coated fabrics were characterized using a variety of flammability test methods, and found to be significantly greater than the uncoated control fabrics. The 20 bilayers for treated cotton fabrics passed the vertical and $45^{\circ}$ angle flame test when add-on values were 5.80, 7.22 and 9.59 $w t \%$ add-on. In all cases, the char lengths of treated fabrics were less than $50 \%$ of the original length of $30 \mathrm{~cm}$ and the after-flame and after-glow times were between 0 and 2 seconds. TGA-FTIR techniques were performed to present volatile depolymerization by thermal degradation for the treated cotton fabric with casein, BPEI, urea and DAP. The results showed that most evolved gases are from flammable substances, which are products of the depolymerization of cotton cellulose. These initial results lay the groundwork for scale-up and future development of commercial grade systems capable of continuously applying functional nanocoatings to a wide variety of substrates.

\section{Acknowledgements}

The authors would like to acknowledge the U.S. Department of Agriculture for financial support of this work.

\section{References}

[1] Wakelyn, P. J. et al. (2006) Cotton Fibers Chemistry and Technology 1st ed., CRC Press, Boca Raton, FL, USA.

[2] https://www.fibre2fashion.com/industry-article/3085/retailuses-of-cotton.

[3] Bourbigot, S. Flame Retardancy of Textiles: New Approaches. In: Horrocks, A. R. and Price, D., Ed., Advances in Fire Retardant Materials, Woodhead Publishing, Cambridge, UK, 2009. 9-40.

[4] Horrocks, A. R. Flame Retardant Challenges for Textiles and Fibres: New Chemistry versus Innovatory Solution. Polymer Degradation and Stability. 2011. Vol. 96, 377-392.

[5] Horrocks, A. R., Kandola, B. K., Davies, P. J., Zhang, S. and Padbury, P. A. Developments in Flame Retardant Textiles - a Review. Polymer Degradation and Stability. 2005. Vol. 88, 312.

[6] Weil, E. D. and Levchik, S. V. Flame Retardants in Chemical Use or Development for Textiles. Journal of Fire Sciences. 2008. Vol. 26, 243-281.

[7] Reeves, W. A., Perkins, R. M., Piccolo, B. and Drake, G. L. Some Chemical and Physical Factors Influencing Flame Retardancy. Textile Research Journal. 1970. Vol. 40, 223-231.

[8] Yang, C. Q. and Qiu, X. Flame-retardant Finishing of Cotton Fleece Fabric: Part I. The use of a hydroxyl-functional organophosphorus oligomer and dimethyloldihydroxylethyleneurea. Fire and Materials. 2007. Vol. 31, 67-81.

[9] Kishore, K. and Mohandas, K. Action of Phosphorus Compounds on Fire-retardancy of Cellulosic Materials: A Review. Fire and Materials. 1982. Vol. 6, 54-58.

[10] Carosio, F., Blasio, A. D., Cuttica, F., Alongo, J. and Malucelli, G. Flame Retardancy of Polyester and PolyesterCotton Blends Treated with Caseins. Industrial \& Engineering Chemistry Research. 2014. vol. 53, 3917-3923.

[11] Malucelli, G., Bosco, F., Alongi, J., Carosio, F., Blasio, A. D., Mollea, C., Cuttica, F. and Casale, A. Biomacromolecules as Novel Green Flame Retardant Systems for Textile: an Overview. RSC Advances. 2014. Vol. 4, 46024-46039.

[12] Parikh, D. V.; Calamari, T. A.; Peterson, D. B. FR/Resilient perpendicular-laid nonwovens containing cotton. AATCC Review. 2002. Vol. 2, 33-37.

[13] Gaan, S. and Sun, G. Effect of Phosphorus Flame Retardants on Thermo-Oxidative Decomposition of Cotton. Polymer Degradation and Stability. 2007. vol. 92, 968-974.

[14] Decher, G., Hong, J., and Schmitt, J. Buildup of ultrathin multilayer films by a self-assembly process: III. Consecutively alternating adsorption of anionic and cationic polyelectrolytes on charged surfaces. Thin Solid Films, 1992. Vol. 210/211, 831-835. 
[15] Decher, G., Lehr, B., Lowack, K., Lvov, Y., and Schmitt, J. New nanocomposite films for biosensors: Layer-by-layer adsorbed films of polyelectrolytes, proteins or DNA. Biosensors and Bioelectronics. 1994. vol. 9, 677-684.

[16] Kong, W., Zhang, X., Gao, M., Zhou, H., Li, W., and Shen, J. A new kind of immobilized enzyme multilayer based on cationic and anionic interaction. Macromolecular Rapid Communication. 1994. Vol. 15, 405-409.

[17] Mao, N. Towards objective discrimination \& evaluation of fabric tactile properties: Quantification of biaxial fabric deformations by using energy methods. Proceedings of AUTEX 2014.

[18] Uğur, S. S., Sariisik, M., and Aktas, A. H. Nano- $\mathrm{Al}_{2} \mathrm{O}_{3}$ multilayer film deposition on cotton fabrics by layer-by-layer deposition method. Materials Research Bulletin. 2011. vol. $46,1202-1206$

[19] Uğur, S. S. et al. Modifying of Cotton Fabric Surface with Nano-ZnO Multilayer Films by Layer-by-Layer Deposition Method. Nanoscale Research Letter. 2010. Vol. 5, 1204-1210.

[20] Wang, Q.; Hauser, P. J. Developing a novel UV protection process for cotton based on layer-by-layer self-assembly. Carbohydrate Polymer, 2010. Vol. 81, 491-496.

[21] Leng, B., Shao, Z., de With, G., and Ming W. Superoleophobic Cotton Textiles. Langmuir. 2009. Vol. 25, 2456-2460.

[22] Zhao, Y., Tang, Y. Wand, X and Lin, T. Superhydrophobic cotton fabric fabricated by electrostatic assembly of silica nanoparticles and its remarkable buoyancy. Applied Surface Science. 2010. Vol. 256, 6736-6742.

[23] Zandi, M., Hashemi, S. A., Aminayi, P. and Hosseinali, F. Microencapsulation of disperse dye particles with nano film coating through layer by layer technique. Journal of Applied Polymer Science. 2011. Vol. 119, 586-594.

[24] Cerkez, I., Kocer, H. B., Worley, S. D., Broughton, R. M. and Huang, T. S. N-Halamine Biocidal Coatings via a Layer-byLayer Assembly Technique. Langmuir. 2011. Vol. 27, 40914097.

[25] Joshi, M., Khanna, R. and Jha K. Chitosan nanocoating on cotton textile substrate using layer-by-layer self-assembly technique. Journal of Applied Polymer Science2011. Vol. 119, 2793-2799.

[26] Chang, S., Slopek, R., Condon, B. and Grunlan, J. Surface Coating for Flame-Retardant Behavior of Cotton Fabric Using a Continuous Layer-by-Layer Process. Industrial Engineering Chemistry Research. 2014. Vol. 53, 3805-3812.

[27] Li, Y-C., Schulz, J., Mannen, S., Delhom, C., Condon, B., Chang, S., Zammarano, M., and Grunlan, J. Flame Retardant Behavior of Polyelectrolyte-Clay Thin Film Assemblies on Cotton Fabric. ACS Nano. 2010. Vol. 4, 3325-3337.
[28] Li, Y-C., Mannen, S., Morgan, A. B., Chang, S., Yang, Y-H, Condon, B., and Grunlan, J. Intumescent All-polymer Multilayer Nanocoating Capable of Extinguishing Flame of Fabric. Advanced Materials. 2011. Vol. 23, 3926-3931.

[29] Carosio, F., Alongi, J., and Malucelli, G. $\alpha$-Zirconium phosphate-based nanoarchitectures on polyester fabrics through layer-by-layer assembly. Journal of Materials Chemistry. 2011. Vol. 21, 10370-10376.

[30] Minimum oxygen concentration to support candle-like combustion (2009). American Society for Standards and Testing, ASTM D 2863-09.

[31] Standard test method for flame resistance of textiles (2001). American Society for Standards and Testing, ASTM D-123001 .

[32] Standard test method for flame resistance of textiles (Vertical Test) (2011). American Society for Standards and Testing, ASTM D-6413-11.

[33] Chen, Y., Frendi, A., Tewari, S. S. and Sibulkin, M. Combustion Properties of Pure and Fire-retarded Cellulose. Combustion and Flame. 1991. Vol. 84, 121-140.

[34] Bajaj, P. Heat and flame protection. In: Horrocks, A. R. and Anand, S. C., Eds., Handbook of Technical Textiles, Woodhead Publishing and CRC Press, Boca Raton, FL, USA, 2000. 223-263.

[35] Purser, D. and Horrocks, A. R. Toxicity of fire retardants in relation to life, safety and environmental hazards and Textiles. In: Horrocks, A. R. and Price, D., Eds., Fire Retardant Materials, CRC Press, Boca Raton, FL, USA, 2001. 62-181.

[36] Nguyen, T. M., Chang, S., Condon, B., Slopek, R., Graves, E. and Yoshioka-Tarver, M. Structural Effect of Phosphoramidate Derivatives on the Thermal and Flame Retardant Behaviors of Treated Cotton Cellulose. Industrial \& Engineering Chemistry Research, 2013. Vol. 52, 4715-4724.

[37] Faroq, A. A., Price, D., Milnes, G. J. and Horrocks, A. R. Thermogravimetric Analysis Study of the Mechanism of Pyrolysis of Untreated and Flame Retardant Treated Cotton Fabrics under a Continuous Flow of Nitrogen. Polymer Degradation and Stability, 1994. Vol. 44, 323-333.

[38] Wang, S., Liu, Q., Luo, Z., Wen, L. and Cen, K. Mechanism study on cellulose pyrolysis using thermogravimetric analysis coupled with infrared spectroscopy. Frontiers of Energy and Power Engineering in China. 2007. Vol. 1, 413-419.

[39] Shen, D. K. and Gu, S. The mechanism for thermal decomposition of cellulose and its main products. Bioresource Technology. 2009. Vol. 100, 6496-6504. 